\title{
Resenha do livro: \\ PEREIRA, Maria de Fátima Rodrigues. Formação de professores: debate e prática necessários a uma educação emancipada. Chapecó, SC: Argos, 2010.
}

\section{Resenha de: \\ Adolfo Ignacio Calderón ${ }^{1}$ e Heloísa Poltronieri ${ }^{2}$ \\ Programa de Mestrado em Educação da Pontifícia Universidade Católica de Campinas (PUC-Campinas).}

Falar de uma obra instigante, desafiadora e questionadora, com elevado fôlego teórico, como é o livro ora resenhado, exige que falemos um pouco de Maria de Fátima Rodrigues Pereira, arguta, séria e engajada pesquisadora de nacionalidade portuguesa, profunda conhecedora da história da educação do nosso país que, por meio da Editora Argos, nos oferece uma obra que desde já se constitui uma leitura obrigatória para a compreensão da formação de professores no país.

Mais do que uma pesquisadora, Maria de Fátima é uma educadora que trabalhou durante mais de vinte anos na rede pública de ensino, atuando como docente e em cargos de direção, fato que lhe possibilita ter uma visão diferenciada da realidade educacional do país. Formou profissionais, em nível de graduação, não somente em sua terra natal, na Universidade de Coimbra, mas também na Universidade de Contestado, no sul do país. Após seu doutoramento em Educação, na Universidade Estadual de Campinas, sob orientação do Prof. Dr. José Claudinei Lombardi, começou a formar mestres em educação no Programa de Mestrado e Doutorado da Universidade Tuiuti do Paraná, instituição onde atualmente atua.

O engajamento político, profundamente comprometido com a mudança social, é a marca característica da sua produção científica. Isso se evidencia nos trabalhos que periodicamente divulga no Boletim Germinal - On Line, publicação Eletrônica do Grupo de Estudos e Pesquisa Marxismo, História, Tempo Livre e Educação (MHTLE), da Universidade Estadual de Londrina, grupo do qual é pesquisadora.

Esse engajamento político, próprio de intelectuais orgânicos, não poderia deixar de ser parte da alma da obra em questão, elaborada por uma autora movida sobretudo, como ela mesma nos confessa, pelo "desejo e compromisso de esclarecer que a formação e o trabalho dos professores podem ser colocados ao serviço de uma sociedade em que homens e mulheres não estejam em relações alienadas de produção da vida; antes, em modos de existência emancipados".

O livro Formação de professores: debate e prática necessários a uma educação emancipada é resultado de uma tese de doutorado das antigas, daquelas que dificilmente vemos serem defendidas hoje, uma tese que resulta do processo de amadurecimento acadêmico-científico de uma vida. Portanto, não é qualquer livro, não é uma tese qualquer, dessas que, muitas vezes, ou na maioria das vezes, são apressadas pelas políticas de produtividade aos quais os formadores e os programas de mestrados e doutorado deste país, encontram-se submetidos.

O livro é resultado de um estudo desenvolvido ao longo de dez anos, no qual a autora busca analisar a formação de professores no Estado de Santa Catarina, entre a década de 1960 e 2002, considerando a relação Estado-formação de professores à luz da 
trama da política em âmbito nacional, superando o que a autora chama de "história em migalhas".

O interesse por essa investigação surgiu a partir da análise das Propostas Curriculares do Estado de Santa Catarina dos anos de 1991 e 1998, que evidenciaram diferenças radicais entre seus fundamentos teóricos. A autora se pergunta, então, como tais antagonismos poderiam estar presentes em documentos elaborados em conjunto com professores. Eis que surge o desejo de desvelar a formação de professores como uma categoria de trabalhadores responsáveis pela educação formal.

A obra encontra-se dividida em três capítulos. No primeiro, intitulado $A$ desoneração e o controle do Estado de Santa Catarina às décadas de 1960 e 1970, a autora analisa a atuação de aparelhos estaduais que operaram na desoneração e controle do Estado na formação de professores, criados em um período em que foi feita a reorganização do Estado e da produção.

O período se caracteriza pela ampliação da formação de professores no nível superior do ensino, necessária devido à expansão dos anos de escolaridade do ensino fundamental e pela visão de educação como essencial para o desenvolvimento econômico do país.

Na década de 1960, o Estado de Santa Catarina viveu a expansão de setores consolidados, como o têxtil, de madeira, carvão e alimentos, ampliando o setor industrial e expandindo a demanda por trabalho intensivo. Conjuntamente com esse processo, ocorreu o que se convencionou chamar de revolução verde, que consistiu na chegada do setor agrícola extrativista aos campos para realização de experiências de genética vegetal. Tal processo culminou na transformação das tecnologias e práticas de trabalho no campo, que acabou por excluir os pequenos proprietários e produtores rurais. Esses trabalhadores excluídos migraram para as periferias da cidade e constituíram-se em mão de obra que precisava do oferecimento de educação escolar. Diante disso, a escola se expandiu e, como consequência, a formação de professores também.

Conforme a autora, para atender a essa nova situação, o Estado realizou um amplo e estruturado planejamento, feito com assessoria da CEPAL (Comissão Econômica para América Latina e o Caribe) e da Agência dos Estados Unidos para o Desenvolvimento Internacional, resultando nos seguintes planos: PLAMERG (Plano de Metas do Governo) I, no governo Celso Ramos, PLAMERG II no governo de Ivo Silveira e o Projeto Catarinense de Desenvolvimento (PCD) no governo de Colombo Machado Salles.

Neste contexto, a formação de professores em nível superior é caracterizada pela desoneração e pelo controle do Estado. A desoneração foi realizada principalmente por meio da criação de um sistema de fundações educacionais, o sistema Acafe (Associação Catarinense das Fundações Educacionais) que, desde a década de 1970, vêm se responsabilizando por $70 \%$ do ensino superior catarinense. A autora cita, também, outros mecanismos que fortaleceram o controle e a desoneração do Estado em relação ao ensino superior e, consequentemente, à formação dos professores como o Conselho Estadual de Educação (CEE), a Lei do Sistema Estadual de Educação e o Primeiro Plano Estadual de Educação.

No segundo capítulo, $O$ controle e resistência à desoneração e ao controle do Estado na formação de professores em nível superior- a década de 1980, a autora destaca os movimentos sociais, que desde a década de 1980, apresentam-se fortemente organizados no Estado. Neste período, observou-se um crescimento na organização de movimentos 
sociais que ofereceram resistência à reforma agrária conservadora, a ampliação da industrialização e a extração da mais-valia.

Para Maria de Fátima, a década de 1980, se não foi fértil para o capital como as duas décadas anteriores, foi rica em manifestações e reivindicações de classe dos movimentos sociais. Sindicatos do vestuário e calçados, dos setores bancários e carboníferos e dos professores inscreveram as suas lutas não somente na conquista de melhores condições de trabalho, mas também nas mudanças dos rumos políticos do país, uma vez que esses grupos se organizaram durante o auge do regime militar implantado em 1964.

Dentre esses movimentos, a autora registra a Novembrada, organizado por estudantes do Diretório Central da Universidade Federal de Santa Catarina (UFSC) e alguns professores, movimento este que ficou conhecido por compor o quadro do cenário de resistência à desoneração e ao controle do Estado da formação de professores.

Este foi o início do processo chamado de "democratização na educação catarinense", durante o qual professores estaduais propuseram que o Estado se onere de sua formação, reivindicaram participação de representação na Secretaria de Educação e no CEE e desvinculação da educação da formação para a produção.

Esses grupos se organizaram na Associação dos Licenciados de Santa Catarina (ALISC), mobilizando toda a categoria de educadores por meio de encontros regionais e estaduais, impondo ao governo, inicialmente de Bornhausen e depois de Amin, o Estatuto do Magistério e um Plano de Carreira.

Suas reivindicações, que incluíam mudanças na composição e na representatividade dos membros da CEE, que deveriam ser de todo o Estado e ter representação das categorias de trabalhadores ligados à educação e acento na CEE, não se concretizam. O governo de Amim aderia às reivindicações apenas no discurso, não havendo, contudo, nenhuma atitude concreta. Ao final desse processo, afirmava-se o controle e a desoneração da formação de professores por parte dos interesses do capital.

A autora destaca, ainda, que o movimento dos educadores era possuidor de ideologias contaminadas, permeado pelo senso comum. Prevalecia o entendimento de que para controlar o aparelho do Estado era preciso apenas haver participação. Para Maria de Fátima, esse movimento teve ausência de visão crítica dos seus representantes.

No terceiro capítulo, A afirmação do controle e da desoneração do Estado para a formação de professores- a década de 1990, a autora ressalta que o país vivia o momento da Reforma do Estado brasileiro, ou seja, de reorganização da crise de acumulação com a implantação do ideário pós-moderno e neoliberal. Em Santa Catarina, as propostas neoliberais começaram a ser implantadas no início da década de 1990, no governo de Kleinubing.

Neste contexto, a autora aponta que foi possível observar a reafirmação da desoneração e do controle do Estado no que tange a formação de professores, pois se concretizaram políticas que são próprias do capital monopolista e que atendem aos interesses integracionistas e internacionais próprias do capital monopólico imperialista, com acento máximo dos interesses do capital especulativo. A educação passou a ser vista como mercadoria, acentuando o empresariamento da educação.

Nos dois mandatos do presidente Fernando Henrique Cardoso, o Estado brasileiro sofreu uma profunda reforma, tendo por base a retração do trabalho industrial, da 
substituição do trabalho vivo pelo morto, do aumento de desemprego estrutural, a fim da possibilidade de novos patamares de acumulação de mais valia. Nessa reforma, as políticas sociais foram consideradas serviços não exclusivos do Estado e, assim, o setor educacional passou a ser revisto e adequado aos novos imperativos econômicos.

No contexto das reformas educacionais, a autora destaca que um conjunto de leis, decretos, resoluções e pareceres foram definindo, controlando e desonerando o Estado da formação de professores. Dentre esses, cabe ressaltar o documento "Referenciais para a Formação de Professores/1998" que tratou especificamente da reforma para a formação de professores. O documento trata de desenvolvimento profissional do professor, progressão na carreira, organização da formação inicial e continuada, formação em serviço e formação a distância.

Nessa reforma, o sentido da formação docente passa a ser a busca por competências. A formação está presa à responsabilização por resultados, eficácia na ação pedagógica e capacidade gestionária da ação ensino-aprendizagem. Segundo a autora, estamos longe de um trabalho crítico do professor.

A formação de professores fundamenta-se no ideário do professor prático, reflexivo na prática. Um prático que reflete sobre suas ações e cujos objetivos estão previamente demarcados pela adequação ao mundo produtivo. $\mathrm{O}$ eixo estruturante da formação não são as disciplinas nem o conhecimento, mas sim a flexibilidade de lidar com situações que vem do mundo da produção e do consumo. Maria de Fátima é taxativa nesse ponto. Para ela, diante disso, fecha-se o cerco, a formação torna-se rígida nos eixos estruturantes das demandas e flexível nas respostas dentro dessas demandas. Para ela esse é o golpe de mestre para o controle do trabalho do professor e a alienação deste em relação à sociedade capitalista.

No Estado de Santa Catarina, as políticas neoliberais e o ideário de professor postulado nas propostas nacionais, se expressaram, sobretudo, em um programa de formação de professores leigos que já atuavam nas redes municipais, o Projeto Magister. Mais uma vez o Estado desonera-se da formação superior e observa-se a ampliação da presença do empresariamento no ensino superior.

Como é possível perceber ao longo da resenha, o livro proporciona ao leitor um trabalho de reflexão sobre os rumos da formação de professores, que, segundo a autora, tem sido cada vez mais formatada na razão instrumental da ordem societária do capital, formando os professores em uma visão mercadológica que tende a torná-los alienados. Maria de Fátima defende veementemente a necessidade de romper com a atual ordem num sentido transformador-superador, postulando para uma formação de professores entendidos como trabalhadores de uma totalidade histórica e cuja atividade se inscreve na divisão social do trabalho.

\footnotetext{
${ }^{1}$ Doutor em Ciências Sociais pela Pontifícia Universidade Católica de São Paulo com Pós-Doutorado em Ciências da Educação na Universidade de Coimbra, docente-pesquisador do Programa de Mestrado em Educação da Pontifícia Universidade Católica de Campinas (PUC-Campinas). E-mail: adolfo.ignacio@puc-campinas.edu.br

${ }^{2}$ Mestranda em Educação no Programa de Mestrado em Educação da Pontifícia Universidade Católica de Campinas (PUC-Campinas), bolsista da Coordenação de Aperfeiçoamento de Pessoal de Nível Superior (CAPES). E-mail: helo_poltronieri@hotmail.com
} 